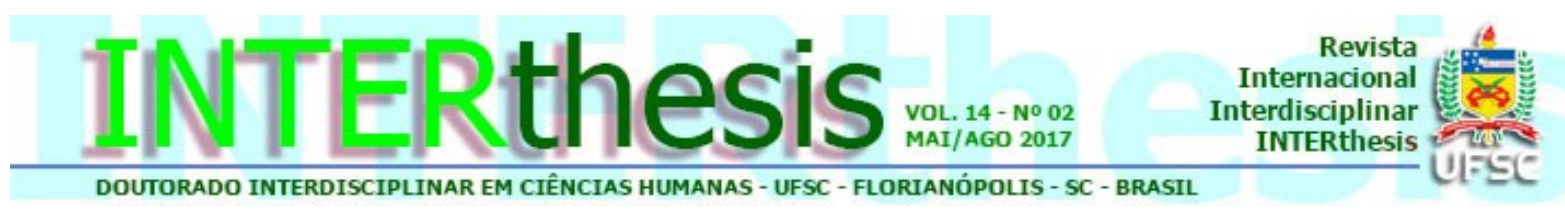

\title{
CINEMA E CIÊNCIA, NATUREZA E CULTURA
}

\section{Resumo:}

Marcio Barreto ${ }^{1}$

Diante de questões contemporâneas que colocam em xeque as fronteiras entre natureza e cultura, homem e máquina, sociedade e ambiente, o cinema é tomado aqui como fio condutor de uma reflexão sobre a ciência moderna a partir de textos de Bergson, Deleuze e outros autores. Operando a passagem da ciência à arte e da arte à ciência, o cinema é aqui assumido como objeto técnico e o objeto técnico como instrumento de ampliação da percepção. A lei da atração gravitacional de Newton, reconhecida como o coroamento da ciência moderna, é tratada no texto em suas implicações físicas e metafísicas a partir de escritos de Betty Dobbs e do próprio Newton para realçar a artificialidade das referidas fronteiras. Através das lentes do cinema, especialmente dos filmes 2001 Uma Odisseia no Espaço, de Stanley Kubrick e Out of the present, de Andrei Ujica, o artigo procura demonstrar a potência do cinema para a percepção de que dimensões da ciência que vão além de suas alianças com o Estado e com o mercado são relevantes para os desafios que despontam no horizonte do século XXI.

Palavras-chave: Cinema. Bergson. Ciência. Newton. Modernidade.

\section{INTRODUÇÃO}

Orientada pela seta do tempo, a vida avançou sobre a matéria, dividiu-se em animal e vegetal e, em cada ramo, criou múltiplas formas de se manifestar. Por um capricho da evolução criativa, deu-se que uma forma inteligente de vida, a humana, espichou seu pescoço e chamou de natureza, a natureza, de pedra, a pedra, de árvore, a árvore, e o homem de homem, que se pôs a encontrar veios de ordem no caos, a dominar relações que construiu na teia dos fenômenos e a isso chamou de ciência. A evolução criativa não se aquietou e pela inteligência escapou uma segunda natureza: a técnica, esse prolongamento dos nossos sentidos.

Não há, entretanto, oposição entre a primeira e a segunda natureza, entre aquilo que tradicionalmente chamamos de natureza e a que se prolonga na tecnosfera, mas está em curso uma reconfiguração do humano e da natureza na medida em que a técnica se desenvolve numa aceleração vertiginosa. Como aponta

\footnotetext{
1 Doutor em Ciências Sociais pela Universidade Estadual de Campinas. Pós-Doutorado na Université Paris-1, Sorbonne, França. Professor da Faculdade de Ciências Aplicadas da Universidade Estadual de Campinas e dos Programas de Pós-graduação do Laboratório de Estudos Jornalísticos, Interdisciplinar em Ciências Humanas e Sociais Aplicadas e do Programa de Lógica e Informação do Centro de Lógica e Epistemologia na mesma universidade em Campinas, SP, Brasil. E-mail: marcio.barreto@fca.unicamp.br
} 
Laymert Garcia dos Santos, é preciso "saber qual é o potencial transformador que existe nas tecnologias, e ao qual você pode acoplar o potencial de transformação do humano" (SANTOS, 2016, p.22). Nas palavras de Gilbert Simondon,"o objeto técnico, pensado e constituído pelo homem, não se limita apenas a criar uma mediação entre o homem e a natureza; ele é um misto estável do humano e do natural, contém o humano e o natural [...]" (SIMONDON, 1969, p.245).

Os objetos técnicos, antes de serem instrumentos de ação no mundo, como armas ou ferramentas, são instrumentos para a ampliação da percepção que modificam nossa relação com o mundo. Nesse sentido, o cinema é descoberta e construção do homem, realização de uma historicidade com potencial de autocriação que submete a humanidade a um novo modo de consciência e de conhecimento, de apreciação e de representação, e sua força está na relação entre o universo desvendado na consciência do espectador e o aparato técnico que o possibilita.

Em sociedades consideradas primitivas, há também tecnologias ampliadoras da percepção: um xamã yanomami, por exemplo, utiliza técnicas insuspeitadas para aceder a dimensões da natureza as quais desconhecemos e, provavelmente por desconhecê-las, entramos numa sinuca ecológica que coloca em xeque a "civilização apoiada exclusivamente na trindade Estado no Mercado e na Ciência" (VIVEIROS DE CASTRO, 2015, p.23). Se uma pena ou uma substância alucinógena extraída da mata podem ser objetos técnicos que permitem a transcendência xamânica, o cinema é, analogamente, um objeto técnico para o acesso a dimensões da realidade em que o tempo liberta o espectador de sua percepção ordinária de si próprio e do mundo.

A antropologia simétrica de Bruno Latour propõe que os modernos sempre fizeram a mesma coisa que fazem os indígenas. Do ponto de vista destes povos, a tecnociência do mundo civilizado aparece numa relação de forças diferente da estabelecida na pretensão de domesticar as forças da natureza. "O aporte mais significativo desta retro antropologia seria uma revisão completa do status ontológico do objeto industrial, tornado objetivo e subjetivo, natural e cultural, técnico e mágico" (GODDARD, 2016).

\section{O CINEMA: FILHO DA CIÊNCIA E PAI DE UMA NOVA ARTE}

R. Inter. Interdisc. INTERthesis, Florianópolis, v.14, n.2, p.19-38 Mai.-Ago. 2017 
A comparação que o filósofo francês Henri Bergson faz entre o mecanismo do cinematógrafo e o modo de operar do pensamento é bastante conhecida: tal como o movimento é artificialmente reconstituído no cinema a partir de fotogramas, de imagens imóveis, a inteligência tem por hábito estratégico paralisar aquilo sobre o que se debruça, recortar o objeto de seu entorno e do fluxo do tempo com os objetivos de analisá-lo e de planejar possíveis ações sobre ele. O mecanismo do pensamento é de natureza cinematográfica, dirá Bergson, pois

[...] tiramos fotografias da realidade e as fazemos desfilar num devir abstrato. Em vez de nos ligarmos ao devir interior das coisas, colocamo-nos fora delas para recompor artificialmente seu devir. [...] Percepção, intelecção e linguagem procedem geralmente assim. Quer se trate de pensar o devir, ou de exprimi-lo, ou mesmo de percebê-lo, não fazemos mais do que acionar uma espécie de cinematógrafo interior (BERGSON, 2001, p. 271).

$O$ parentesco entre o mecanismo do conhecimento inteligente e $O$ do cinematógrafo fica mais evidente quando Bergson observa que a ciência moderna "deve se definir sobretudo pela sua aspiração de considerar o tempo uma variável independente" (BERGSON, 2006, p.41), o que possibilita relacionar cada instante à posição de um móvel ou a outra variável qualquer. O instante, no entanto, é uma abstração, um artifício, é o limite de um intervalo de tempo que tende a zero. Assim, um móvel nunca está numa posição num determinado instante, pois o tempo e o próprio movimento não admitem recortes sem que a continuidade, que lhes é essencial, seja sacrificada. "No que diz respeito ao tempo, a ciência conta os instantes, marca as simultaneidades, mas segue sem apreciar o que se passa durante os intervalos" (BERGSON, 1998, p. 57).

Apesar da artificialidade, o truque da ciência de decompor o tempo de modo que qualquer instante, indistintamente, pode ser equidistante de dois outros, um anterior e outro subsequente, é bem sucedido em suas pretensões de explicar o passado e de prever o futuro. No que diz respeito à decomposição do tempo em instantes, o truque tecnológico do cinematógrafo e seu respectivo sucesso são similares aos da ciência moderna: o que tornou possível o cinema foi a equidistância das imagens fotográficas perfiladas numa fita em cujos furos, também equidistantes, se acoplava a engrenagem do aparelho.

Merleau-Ponty inverterá as premissas de Bergson postulando que nossa percepção espontânea é sintetizadora e não estritamente analítica. Se na analogia 
de Bergson o cinematógrafo tem um mecanismo análogo ao do pensamento analítico, em Merleau-Ponty a percepção opera pela síntese e aí residiria o análogo ao mecanismo do cinema, o qual está fundado na imagem média formada pela sucessão de fotogramas que se misturam na retina do espectador. Apesar da inversão de premissas, o filósofo contemporâneo Mauro Carbone pensa que a conclusão de Merleau-Ponty é similar à de Bergson: "nossa percepção espontânea não é analítica, mas sintetizadora, e é precisamente por isso que podemos considerá-la de natureza cinematográfica" (CARBONE, 2011, p.94).

O cinema é, portanto, filho da ciência: nasce da decomposição do movimento em fotogramas por homens de ciência, como Marey e Londe, que não se interessavam pelo movimento, mas pelas imagens imóveis, pelas fotografias instantâneas tiradas em intervalos de tempo bem reduzidos que permitisse, por exemplo, observar o movimento dos músculos de um membro de um animal entre duas passadas. Por outro lado, o cinema é pai de uma nova arte, pois é capaz de ampliar percepção do espectador e sua relação com o mundo: o cinema pode dar a ver aquilo que, sem o deslocamento que ele opera no olhar ordinário, permaneceria invisível. Como observou Arlindo Machado, "se a percepção do movimento é uma síntese que se dá no espírito e não no mecanismo do olho, o cinema deve ser entendido também como um processo psíquico, um dispositivo projetivo que se completa na máquina interior" (MACHADO, 2013, p. 23).

Combinação entre arte e ciência, os meios artificiais pelos quais o cinema se concretiza não implicam a artificialidade do seu resultado. $O$ cinema não é apenas uma arte de espetáculo, um espelho do frenesi da modernidade, e sim, como afirmou em meados do século passado o cineasta e teórico do cinema Jean Epstein, "um instrumento privilegiado que, como a luneta ou microscópio, revela aspectos do universo até então desconhecidos" (EPSTEIN, 1974, p.17).

O cinema, mais do que reconstituir o tempo cronológico decomposto nas imagens instantâneas dos fotogramas, pode subvertê-lo. Gilles Deleuze resgata a importância da obra de Bergson, especialmente Matéria e Memória, para revelar como o cinema fala, pensa e sonha ao apropriar-se do cronômetro e subverter a linearidade dos instantes que ele marca. Deleuze considera Cidadão Kane (EUA, 1941), de Orson Welles, o primeiro grande filme de um cinema do tempo, no qual se observa os "caracteres paradoxais de um tempo não cronológico: a preexistência de 
um passado em geral, a coexistência de todos os lençóis do passado, a existência de um grau mais contraído [do passado]" (DELEUZE, 2005, p.122).

Em Eu te amo, Eu te amo (França, 1968), Resnais traduz a memória em tempo em estado puro através de uma topologia constituída por lençóis do passado. Para Sarah Leperchey, "a reflexão de Deleuze sobre a obra de Alain Resnais em $A$ imagem-tempo insere os filmes do cineasta francês numa perspectiva topológica, pois constrói uma representação particular do tempo na confrontação de diversas camadas do passado, como em Hiroshima mon amour" (LEPERCHEY, 2012, p.198).

$A$ adição de uma dimensão temporal às imagens fotográficas colocou $\mathrm{O}$ cinema dentro dos fenômenos do sonho e do pesadelo. $\mathrm{Na}$ analogia bergsoniana, o mecanismo do pensamento se espelha no do cinematógrafo, mas a consciência do espectador pode ser expandida num espectro que vai da análise inteligente à intuição, do tempo matemático à pura duração, da vigília ao sonho. Se as múltiplas camadas do passado se superpõem em Resnais ou em Visconti (especiamente no proustiano Morte em Veneza - Itália, 1971), se o sonho vem pronto do galpão cristalino de Méliès ou se o pesadelo se reflete no avesso de Hollywood, como em Cidade dos Sonhos (EUA, 2001), de David Lynch, o cinema é indissociável da imagem-sonho: em Um americano em Paris (EUA/França, 1951), Gene Kelly faz a passagem do sonho para o sonho dentro do sonho à medida que seu corpo vai sendo sublimado pela música.

Cinema e sonho também se confundem na conotação de utopia, de anseio, de desejo de conquista e, por fim, de sonho de consumo. A expansão territorial na colonização dos Estados Unidos partiu da Costa Atlântica rumo à Oeste. Chegando ao Pacífico, não havendo mais terras a serem conquistadas, dirá Paul Virilio, novos horizontes alternativos serão inventados

\begin{abstract}
quando um certo senhor Wilcox registra, em 1903, no estado da Califórnia, um loteamento de aproximadamente 700 habitantes que logo a senhora Wilcox batiza de Hollywood, porque, como ela diz, 'o azevinho traz felicidade'. Será, portanto, nesse longínquo subúrbio de Los Angeles que a nação americana haverá de continuar 'por outros meios' sua marcha sem fim, sua viagem sem volta [...] (VIRILIO, 1999, p. 28).
\end{abstract}

O sonho empobrece modulado por forças que o aprisionam. Em depoimento recolhido na aldeia em que vive, o xamã Davi Kopenawa aponta para o empobrecimento da capacidade de sonhar dos Brancos, que se limita ao sonho de posse. A habilidade para sonhar dos yanomamis é transmitida através das gerações: 
"É o nosso estudo que nos ensina a sonhar. Deste modo, quem não bebe o sopro dos espíritos tem o pensamento curto e enfumaçado; quem não é olhado pelos xapiripë não sonha, só dorme como um machado no chão" (KOPENAWUA, 1998).

Sonho de machado: sonho de destruição para incrementar o consumo. $O$ próprio cinema, na tentativa de engendrar o sonho compensatório do frenesi e da tensão da vida moderna, acaba frequentemente por reproduzir na tela a iconoclastia da modernidade. Não obstante, ao "esculpir o tempo" (TARKOVSKI, 1990, p.72), o diretor de cinema pode lidar com a dimensão onírica num grau de complexidade análogo ao que o xamã tem acesso. É o que faz Stanley Kubrick em 2001 - Uma Odisseia no Espaço (EUA, 1968).

\section{2001- UMA ODISSEIA NO ESPAÇO E A GRAVITAÇÃO UNIVERSAL}

A lei da gravitação universal de Newton, segundo a qual a força gravitacional varia com o inverso do quadrado das distâncias, representou o sucesso da ciência moderna, sua capacidade de revelar o modo como a natureza funciona. Os trabalhos da química e historiadora norte-americana Betty Jo Teeter Dobbs e de seu precursor e compatriota, Richard Westfall, têm sido fundamentais para a formação do corpo conceitual da física de newtoniana.

Da máxima dos alquimistas, o que está em cima é como o que está embaixo, impressa na Tábua de Esmeralda e atribuída a Hermes Trismegisto, Newton extraiu a essência da gravitação universal. Ele aplicou ao cosmo (em cima) o conceito de espírito universal (embaixo), "que era nada mais nada menos que o agente pelo qual Deus exercia o seu providencial cuidado entre os átomos" (DOBBS, 1984, p.511), um espírito "através de cuja força e ação as partículas dos corpos se atraem a mínimas distâncias e permanecem unidas [...]" (NEWTON, 1987, p. 785).

A teologia foi tão relevante quanto a alquimia para o conceito newtoniano de força à distância. Deus exerceria a atração entre os corpos, não o Deus cartesiano que pôs o Universo em movimento e colocou-se numa posição externa a ele para observar o automatismo de sua obra, mas um Deus panteísta, que age constantemente no universo, reafirmando sua obra, fazendo do espaço Seu sensorium, agindo constantemente através de leis fundamentais cujos enunciados são o Seu próprio discurso nos fenômenos de escala cósmica e nos de dimensões moleculares. No início do século XX, Einstein ficou intrigado com o fato da lei da 
atração gravitacional pressupor que a gravidade seria transmitida numa velocidade infinita, mas isso não seria uma dificuldade para Deus onipresente, onisciente e agente transmissor da força, como Newton sugeriu no Escólio Geral e na Questão 31 de Óptica.

Apoiado em cálculos decorrentes da lei da gravitação universal, Newton se debruçou sobre as Escrituras para apontar alterações que as corremperam ao longo dos séculos. No problema XX da proposição XXXIX do livro III do Principia, ele afirma que a "marcha anual do movimento de precessão da Terra é de 50", ou seja, $1^{\circ}$ a cada 72 anos" (NEWTON, 1987, p.722), valor que servirá em seu livro As profecias do Apocalipse e o Livro de Daniel para colocar em xeque a data estipulada pela Igreja para o nascimento do Cristo: o nascimento do Cristo teria sua data fixada no mesmo dia em que os pagãos festejavam o solstício de inverno, mas como o movimento de precessão alterou as datas dos solstícios e dos equinócios, os dois eventos deixaram de coincidir.

A aposta que o Renascimento fez na potência da razão para criar um novo sistema-mundo não descartava, a princípio, a metafísica. Aos poucos, especialmente após o sucesso do equacionamento desta lei da natureza, a ciência moderna vai substituindo a visão mágica do mundo pela objetiva funcionalidade das relações determinísticas de causa e efeito, moldando-se progressivamente às concepções de desenvolvimento econômico e à sua aplicabilidade na esfera políticomilitar. Das aplicações práticas da teoria newtoniana, as viagens espaciais são as que mais lembram a lei da gravitação universal, como verbalizou o personagem de Tom Hanks no filme Apollo 13 (EUA, 1995), em alusão a Willian Anders, piloto do módulo lunar da missão Apollo 8: "I think Isaac Newton is doing most of the driving right now"2.

A dimensão do sagrado que envolvia as reflexões de Newton, Giordano Bruno e outros filósofos do Renascimento, foi se convertendo ao longo dos séculos seguintes, na aposta em que a ciência poderia oferecer não apenas as explicações de como o universo funciona, mas também as de porque ele existe e que sentido ele faz. O fetiche que a tecnologia exerce sobre as pessoas e, em última instância, o

\footnotetext{
2 Transcrição do áudio da missão, quinto dia.

Disponível em: http://history.nasa.gov/ap08fj/18day5 green.htm Acesso em 30 Jul. 2016.
} 
próprio fetiche da mercadoria, são atualizações e empobrecidas desta longínqua conversão.

Apesar da percepção que o senso comum tem de que a ciência nos últimos séculos abriu um caminho vitorioso no controle dos fenômenos naturais à medida que eliminou a magia de seu domínio,

\begin{abstract}
por maiores que sejam as realizações da filosofia mecanicista, um elemento dialético antes presente no pensamento científico, uma percepção do irracional (no sentido do que é inexplicável do ponto de vista mecânico) se perdeu quando ela triunfou, e o nosso século está tentando recuperar, a que duras penas (HILL, 1987, p. 283).
\end{abstract}

À medida que a ciência eliminava a magia de suas esferas, o sistema racional e representativo, com todos os seus limites apriorísticos apontados por Kant, ganhava vigor movido pelo impacto de suas conquistas tecnológicas. É esse sistema coagulado em HAL que patina em 2001 - Uma Odisseia no Espaço (EUA, 1968), filme dirigido por Stanley Kubrick.

O ponto de vista dominador da ciência moderna em sua pretensão de domesticar os fenômenos da natureza resplandece na rotação contemplativa da estação espacial diante da imagem da Terra, conforme a figura 1. O giro da nave tem a função de simular a gravidade dentro da estação, criando um peso efetivo que age sobre os astronautas. Mesmo estando no espaço sideral, na ausência de campos gravitacionais externos, eles caminham como se existisse uma força que os prendesse ao chão da espaçonave.

O cuidado de Kubrick com a gravidade faz ressoar no filme, especialmente nesta cena, a questão que foi decisiva para o coroamento da ciência moderna: ao equacionar a força de atração gravitacional, Newton derrubou as barreiras que separavam céu e terra. Entretanto, a ciência moderna triunfou substituindo o nosso mundo de qualidades e percepções sensíveis pelo da quantidade e da geometria deificada.

Assim, o mundo da ciência - o mundo real - se separou do mundo da vida. $\mathrm{Na}$ realidade esses dois mundos estão unidos pela práxis, mas separados por um abismo. É nisto que consiste a tragédia do espírito moderno que desvendou o enigma do Universo, mas para substituí-lo por outro enigma: o de si próprio. (KOYRÉ, 1968, p.96).

O enigma de si próprio em que a leitura predominantemente científica dos fenômenos nos deixa é levado ao limite no filme de Kubrick até romper a membrana que separa os dois mundos aos quais Koyré se refere. O sistema racional tecnológico é encarnado pelo computador HAL como um grande mundo-cérebro. A R. Inter. Interdisc. INTERthesis, Florianópolis, v.14, n.2, p.19-38 Mai.-Ago. 2017 
longa citação abaixo é fundamental para explicitar aquilo que no cinema aparece como potencial de percepção sobre a ciência nos termos que aqui nos interessa.

\begin{abstract}
É que, em Kubrick, o próprio mundo é um cérebro, há identidade entre cérebro e mundo, como a grande mesa circular e luminosa de Doutor Fantástico, o computador gigante de 2001 Uma odisseia no espaço, o hotel overlook de $O$ iluminado. [...] Mas, se o cálculo fracassa, se o computador falha, é porque o cérebro não é um sistema razoável, tampouco o mundo um sistema racional. A identidade do mundo e do cérebro, o autômato, não forma um todo, antes um limite, uma membrana que põe em contato o fora e o dentro [...]. O dentro é a psicologia, o passado, a involução, toda uma psicologia das profundezas que mina o cérebro. O fora é a cosmologia das galáxias, o futuro, a evolução, todo um sobrenatural que faz o mundo explodir. As duas forças são forças de morte que [...] em última análise se tornam indiscerníveis. [...] A menos que se opere uma reconciliação em outra dimensão, uma regeneração da membrana que apaziguasse o fora e o dentro, e recriasse um mundo-cérebro como um todo em harmonia com as esferas (DELEUZE, 2005, p.245).
\end{abstract}

Como o retorno épico de Ulisses para casa em Odisseia, a viagem de Bowman é narrada numa estrutura de linguagem sem linearidade, da qual o espectador participa em dois planos: um cósmico, épico, em que o espírito se expande em infinitos de múltiplas cardinalidades, e outro interno, o das alegrias e mazelas do cotidiano que Drumond sintetizou na expressão "vida besta" (DRUMOND, 2013, p.21) e que se revela nas ligações telefônicas do Dr. Floyd para sua filha e do Dr. Poole para seus pais, as quais curto-circuitam a viagem no espaço e a vida ordinária terrestre.

A inquietude interior de Bowman o leva ao encontro com ele próprio num ambiente estilo neoclássico que contrasta com seus paramentos de astronauta. No final, "é conforme uma quarta dimensão que a esfera do feto e a esfera da terra têm chance de entrar numa nova relação incomensurável, desconhecida, que converteria a morte numa nova vida" (DELEUZE, 2005, p.246). Uma nova relação que convertesse, enfim, o conhecimento em novas configurações de híbridos como natureza e tecnologia, humanidade e objeto técnico, arte e ciência, afetos e conceptos, numa dimensão em que haveria complementaridade entre as vias inteligente e intuitiva de acesso ao conhecimento. Uma nova relação simbolizada pela nave espacial que, ao final do filme, tem o formato de um espermatozoide, o qual fecundará a Terra para o retorno do feto, para o início desta nova relação.

Em O sétimo selo (Suécia, 1956), de Bergman, a mente de Antonius Block também patina na dúvida sobre a existência de Deus. Entregue às próprias forças de seu pensamento, sua fé é abalada pela exigência de uma prova racional da existência de Deus. Impotente para a transcendência religiosa, Block é paralisado R. Inter. Interdisc. INTERthesis, Florianópolis, v.14, n.2, p.19-38 Mai.-Ago. 2017 
pela dúvida como Hamlet fora imobilizado por Shakespeare diante das incertezas que o perturbavam.

Paralisar para analisar: o artifício bem sucedido da ciência de fazer do tempo uma variável independente permitiu ao homem controlar quantidades de energia infinitamente superiores às da escala antropométrica e contornar obstáculos ao sucesso da espécie humana no planeta, mas revelou-se incompleto. Para responder às questões que despontaram em meados do século $X X$, com o espanto da bomba atômica e com a clareza da contradição entre os limites dos recursos naturais do planeta e a lógica do consumo como motor da economia, seriam preciso novas relações entre natureza e cultura, sociedade e ambiente e homem e máquina.

Parece faltar ao avanço vertiginoso da técnica uma espécie de "contrapartida moral", como afirmou Bergson:

Se nossos órgãos são instrumentos naturais, nossos instrumentos são por isso mesmo órgãos artificiais. [...] Porém, máquinas que [...] convertem em movimento energias potenciais acumuladas durante milhões de anos, vieram dar ao nosso organismo uma extensão tão vasta e uma potência tão formidável, tão desproporcional à sua dimensão e força, que certamente nada disso havia sido previsto no plano estrutural de nossa espécie: foi um acaso único, a maior conquista material do homem no planeta. [...] Ora, nesse corpo desmesuradamente aumentado, a alma continua o que era, demasiado pequena agora para enchê-lo, muito frágil para dirigi-lo. [...] seriam necessárias novas reservas de energia potencial, mas agora de natureza moral (BERGSON 1978, p.256).

Temos, portanto, uma ciência incompleta. Walter Benjamin recebeu o advento da guerra de trincheiras como expressão daquilo que julgava lamentável no "monstruoso desenvolvimento da técnica" (BENJAMIN, 1987, p.115) associado às devastações da então recente primeira guerra mundial. Em 1936, ele parece crer que "a sociedade não estava suficientemente madura para fazer da técnica o seu órgão, e que a técnica não estava suficientemente avançada para controlar as forças elementares da sociedade" (BENJAMIN, 1987, p.196).

Amélia Império Hamburger invoca a imagem do ouroboros, figura de uma serpente que faz um círculo que quase se fecha, quase completo, como símbolo da teoria newtoniana da força gravitacional. Segundo ela,

a figura representa a teoria científica de Newton, um todo autoconsciente, formada através do processo de análise e síntese em que a causa mais geral, encontrada pelo método da razão e experiência, é transformada em princípio. [...] Entretanto, a teoria não contém as causas de suas leis, que devem ser investigadas por outros pesquisadores. Por isso o círculo não se fecha (HAMBURGER, 1997, p.64). 
Estudos como os de Dobbs revelaram o quanto a incompletude representada pelo ouroboros abre horizontes tão fascinantes quanto a própria formulação da lei da atração gravitacional. Embora Amélia Hamburger se refira mais especificamente à epistemologia da física, a incompletude à qual se refere pode ser aplicada ao mecanismo do conhecimento que, na análise bergsoniana, privilegia a inteligência em detrimento da intuição. O que Bergson chama de "contrapartida moral" à capacidade humana de controlar grandes quantidades de energia não teria sua energia potencial armazenada no mecanismo do pensamento inteligente, mas no seu complemento: no conhecimento intuitivo, na intuição como método de conhecimento.

[...] de fato, na humanidade da qual fazemos parte, a intuição é quase inteiramente sacrificada à inteligência. Parece que, ao conquistar a matéria e ao reconquistar-se a si própria, a consciência teve que esgotar o melhor da sua força. Esta conquista, nas condições particulares em que se realizou, exigiu que a consciência se adaptasse aos hábitos da matéria e concentrasse neles toda sua atenção, enfim, que se determinasse mais especialmente em inteligência. No entanto, a intuição está presente, mas vaga e sobretudo descontínua [...] (BERGSON, 2001, p.240).

A ciência acentuou seu caráter utilitário em sua aliança com o capital, alijando de seu corpo de valores toda forma de conhecimento que não se insira nos mecanismos de produtividade e seus respectivos indicadores. Davi Kopenawa anuncia aos Brancos a queda do céu, expressão que dá título ao livro escrito por ele em parceria com o antropólogo Bruce Albert. Suas antenas captaram o recado da mata, mas, ao transmiti-lo, percebe que seus interlocutores não são capazes de decodificá-lo, pois suas antenas não reconhecem os sinais gerados por formas de conhecimento não reconhecidas pela ciência.

Como ouvir recado do xamã se as antenas da percepção no mundo civilizado estão magnetizadas pelo desejo de consumo? O dramaturgo Heiner Müller afirmou a Jean-François Peyret em 1983 que "o pensamento é sempre mais lento do que a escrita poética" (apud SANTOS, 2003, p.247). Talvez pudéssemos analogamente dizer que o pensamento é sempre mais lento do que a percepção no cinema.

Em 2001, mesmo que o espectador não o elabore intelectualmente, suas antenas captam a essência do recado de Kopenawa: o monólito é o expoente do mundo-cérebro colocado em xeque na relação entre natureza e cultura. Luis Paulo Piassi vê a oposição semântica fundamental entre natureza e cultura na cena em que o misterioso objeto aparece aos hominídeos: "os elementos céu e solo estão 
associados ao polo natureza, enquanto o monólito está representando o polo cultura" (PIASSI, 2013, p.142). Para Deleuze, no entanto, "a pedra preta é a alma dos três corpos, terra, sol e lua, mas também germe dos três cérebros, animal, humano e maquinal" (DELEUZE, 2005, p.246).

Antes que o espectador possa pensar sobre as questões que emanam da tela, o filme de Kubrick o captura na vertigem do tempo não linear. Em 1968, ano de seu lançamento, o filme fazia ressoar na consciência do espectador os ecos da corrida espacial em plena Guerra Fria, abrindo possibilidades de percepção sobre a ciência em suas dimensões políticas e militares sem, no entanto, abordar diretamente esta questão. Space Race (Inglaterra, 2005), produzido da BBC, explica a corrida espacial e o papel da tecnociência na luta das nações rivais pelo domínio da tecnologia de propulsão e de navegação pelo espaço, enquanto 2001 arrebata o espectador em espírito fazendo reverberar na tela a disputa pela hegemonia do espaço.

\section{OUT OF THE PRESENT: A QUEDA}

Analogamente a 2001, Solaris (União Soviética, 1972), filme de Tarkovski baseado na novela homônima de Stanislaw Lem, apresenta dois planos da viagem do Dr. Chris Kelvin: um em sincronia com o murmúrio de sua vida interior, com a psicologia do seu passado que o atormenta, e outro em que a duração se dilata na imensidão cósmica. Em 2001, é a inteligência e sua capacidade de produzir artefatos que vão aos seus respectivos limites, mas Tarkovski fez sua nave parecida com um ônibus velho se a compararmos com a imponência tecnológica e a assepsia dos veículos espaciais de 2001. Em Solaris, é a intuição e o seu pressuposto, a duração, o tempo fora do tempo, que resolvem a voltagem entre as duas dimensões, a cotidiana e a cósmica, a de dentro e a de fora.

No retorno de Kelvin à casa, céu e terra são conectados pela verticalidade da chuva. Do lado de fora da casa, ele observa seu pai no interior da sala em atividade corriqueira, arrumando livros sobre uma mesa enquanto a chuva que lá dentro cai molha sua roupa. Kelvin permanece seco do lado de fora e vai ao encontro de seu pai na porta da casa onde, ajoelhado, resigna-se diante do tempo reencontrado, dissolvendo a tensão entre o que está em cima e o que está embaixo, entre o dentro 
e o fora. Uma nova relação converte as forças de morte em forças de vida e a câmera se eleva até fundir a imagem aérea da casa no oceano de memória

A questão do eterno retorno e a trilha sonora de 2001 fazem dele um filme nietzschiano. Podemos também considerar Solaris um filme bergsoniano, no sentido em que atualiza a potência do pensamento de Bergson ao tomar as precipitações de memória que vêm do exterior da estação espacial como via de resolução na relação entre o dentro e o fora, especialmente na cena final.

Se o ouroboros representa a incompletude da teoria de Newton e é naquilo que ficou de fora onde podem ser reencontrados fragmentos para uma nova relação entre natureza e cultura, no cinema, analogamente, é no que não é dado, dito, percebido ou apreendido no primeiro plano que parece estar aquilo se mostra mais rápido do que o pensamento. Em O sétimo selo, a dúvida de Antonius Block não remete o espectador diretamente à dúvida hamletiana, tampouco à dessacralização da ciência apontada por Koyré, mas como não ver no malabarista Jof a imunidade perante a peste da dúvida quando mata o pernilongo que rondava seus ouvidos como quem espanta um pensamento? Em Solaris, a questão da memória que subverte o tempo ordinário numa aeronave em ruínas não induz o espectador à reflexão sobre a necessidade de uma nova relação entre natureza e cultura, mas como não perceber a fragilidade do espírito humano diante da tecnologia de propulsão na cena em que Kelvin atrai Hari para o módulo espacial com a intenção de livrar-se da lembrança que o atormenta. 2001 Uma Odisseia no Espaço, por sua vez, não toca diretamente na questão dos limites do mundo-cérebro, mas os referidos filmes contêm virtualmente múltiplas possibilidades para a percepção do espectador adiantar-se ao seu pensamento. Nesse sentido, o cinema é para a o mundo civilizado o que a pena ou o psicotrópico vegetal são para o yanomami: mágico e técnico.

Out of the present, (Alemanha, 1995), dirigido por Andrei Ujica, capta de maneira singular o duplo movimento (à interioridade e à dimensão cósmica da vida) que observamos nos filmes Solaris e 2001, ambos referenciados na obra do cineasta romeno. Ujica filma durante seis meses o cotidiano da estação orbital MIR, tomando o cosmonauta Sergei Krikalev como análogo aos personagens protagonistas de Solaris e de 2001. A estação orbital completa uma volta ao redor da Terra, passando pelo dia e pela noite, em aproximadamente 90 minutos. Como 
não se lembrar da esfera opaca, espécie de cápsula do tempo, de Eu te amo, eu te amo?

Ujica faz uma colagem das imagens que capturou a bordo da MIR. Krikalev não é um ator. Ele vive o distanciamento do planeta e das pessoas que o habitam ao mesmo tempo em que recebe notícias sobre a dissolução da antiga União Soviética e do fervor da política global lá embaixo. Seu distanciamento dos fatos políticos o deixa com a sensação de estar out of the present, mas há outra fonte para este estado em que o cosmonauta se encontra: conforma a figura 1, a aparente ausência de gravidade que ele experimenta estando, no entanto, submetido ao campo gravitacional terrestre é um fenômeno tão paradoxal quanto o sugerido pela contradição entre as palavras fora e presente.

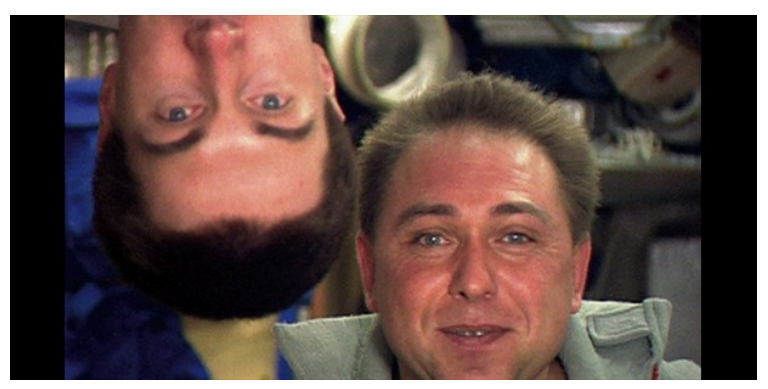

Figura 1: Krikalev (à esquerda) em cena de Out of the present.

A estação orbital está próxima demais do planeta para estar livre dos seus efeitos gravitacionais. A ausência de gravidade vem do fato da nave ter uma velocidade de órbita próxima a $8 \mathrm{Km} / \mathrm{s}$, o que a faz em constante queda, tal qual um satélite. Conforme a figura 2, a queda que acompanha a curvatura do planeta sem com ele se chocar e os efeitos gravitacionais desaparecem.

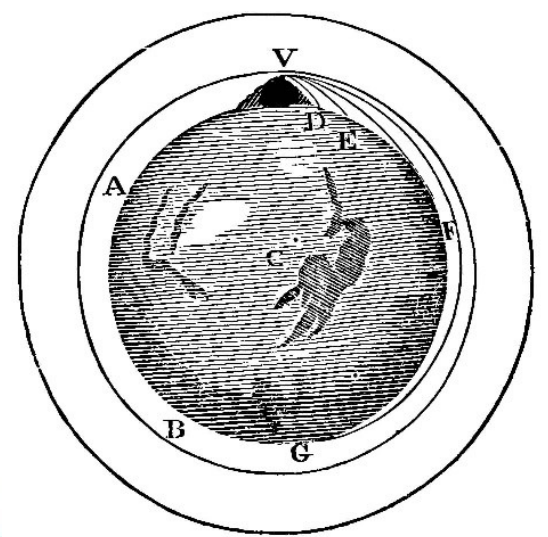

Figura 2: Esquema de Newton sobre a trajetórias de corpos lançados próximos à superfície terrestre.

Ao formular a Relatividade Geral, Einstein partiu do mesmo aparente paradoxo: um corpo observado em queda livre sob a ação de um campo gravitacional está, do ponto de vista de seu próprio referencial, livre de ações 
gravitacionais. Estar fora do presente também é, no caso de Krikalev, estar igualmente dentro e fora de um campo gravitacional.

A queda é um elemento essencial no filme de Ujica, assim como em $O$ Anticristo (Alemanha e Dinamarca, 2009), de Lars Von Trier, Um corpo que cai (EUA, 1958), de Hitchcock, Asas do Desejo (Alemanha, 1987) e Tão longe, tão perto (Alemanha, 1993), ambos de Win Wenders, a queda exerce um protagonismo evidente. Em Out of the presente, a queda ininterrupta virtualmente contém a cada volta da estação orbital possibilidades de complemento na mente do espectador que se abrem num espectro de percepções sobre os pilares da cultura ocidental. Ujica retoma Solaris e 2001 numa vídeo-arte cujas insinuações são mais velozes do que a capacidade de processamento do pensamento do espectador.

A Queda, que para Einstein e para Newton foram centelhas que desencadearam novas teorias da Física, tem importância capital na cultura do Ocidente também devido às Escrituras: a queda do homem do Paraíso, tal como descrita no Gênesis. A expressão queda do céu, que assume nas palavras de Kopenawa um tom apocalíptico, quer dizer, de revelação, representa na cultura ocidental a expulsão do paraíso, a queda do homem do céu, o pecado original, o início da temporalidade, das vicissitudes e dos prazeres da carne, do laço gravitacional com o chão, com o pó de onde viemos e para onde retornaremos. Representa a distinção entre cultura e natureza, pois o bicho que habitamos teria vindo do barro, mas por intervenção divina, diferentemente de outros seres.

O que une na cultura ocidental a importância da Queda para a ciência e para a religião é a imagem da maçã, respectivamente o fruto que revelou da lei da gravidade e o fruto proibido no paraíso. Embora no Gênesis e na obra de Newton não haja qualquer referência a maçãs, a imagem do fruto se impôs como símbolo, como arquétipo de duas Quedas que fundam a religião e a ciência moderna. A maçã é, em última instância, a ética como fruto da árvore filosófica de Descartes, cuja raiz é a metafísica e cujo caule é a física. No entanto, "não devemos mais acreditar em árvores, nem em seus prometidos frutos. Queremos um pouco de terra... já é tempo" (DELEUZE; GUATTARI, 2011, p. 43).

Em 2001, a rotação da estação espacial diante da Terra tem a finalidade de justificar a gravidade aparente nos corpos dos astronautas que caminham presos ao chão da nave, ao invés de flutuarem como a caneta de Floyd durante a viagem até a 
estação no início do filme. No filme de Ujica, ao contrário, a queda ininterrupta simula a ausência de gravidade. E não se trata de encenação: as cenas feitas dentro da estação MIR mostram astronautas em seu trabalho dentro de uma nave que cai ao redor da Terra e cujos pesos estão suspensos, ainda que seus corpos estejam inseridos no campo gravitacional terrestre. No interior da nave, a gravidade é nula, mas a sua queda ininterrupta e seu movimento cíclico subvertem, num só golpe, o tempo e a mais carnal relação que o ser humano tem com o planeta: o seu peso. $O$ protagonismo da gravidade no filme torna incontornável a revisão do pecado original e do triunfo da ciência moderna.

Assim, a vídeo-arte de Ujica insere o espectador no tempo fora do tempo e, antes que o mecanismo do seu pensamento possa processá-la, sua percepção se abre para o que há de essencial nos referidos filmes de Kubrick e de Tarkovski: respectivamente, o limite do mundo-cérebro e o recalque do conhecimento intuitivo. No prefácio da edição brasileira de $A$ Queda do Céu, Eduardo Viveiros de Castro escreveu:

\begin{abstract}
Ao mesmo tempo uma explicação do mundo segundo uma outra cosmologia e uma caracterização dos Brancos segundo uma outra antropologia (uma contra-antropologia), $A$ queda do céu entrelaça estes dois fios expositivos para chegar à conclusão de uma iminência da destruição do mundo, levada a cabo pela civilização que se julga a delícia do gênero humano - essa gente que, liberta de toda 'superstição retrógrada' e de todo 'animismo primitivo', só jura pela santíssima trindade do Estado, do Mercado e da Ciência, respectivamente Pai, Filho e Espírito Santo da teologia modernista" (VIVEIROS DE CASTRO, 2015, p.23).
\end{abstract}

Apesar do justo tom enfático do antropólogo, talvez seja possível evitar a iminente queda do céu reconhecendo nas palavras do xamã a derrocada do mundocérebro colonizado pelo capital e a necessidade da liberação das potências da própria tecnociência para a percepção de nova relação entre natureza e cultura. 


\title{
CINEMA AND SCIENCE, NATURE AND CULTURE
}

\begin{abstract}
:
Faced with contemporary issues that call into question the boundaries between nature and culture, man and machine, society and environment, cinema is taken here as a guide for reflection on modern science by Bergson and Deleuze's texts, among other authors. Operating the passage from science to art and from art to science, cinema is here considered as a technical object and technical object as instrument to magnify perception. To highlight the artificiality of these borders, Newton's gravitational law is presented in its physical and metaphysical implications by the writings of Betty Dobbs and Newton himself. Through the lens of cinema, especially on movies such as 2001 A Space Odyssey, by Stanley Kubrick and Out of the present, by Andrei Ujica, the article shows that the power of cinema contributes to the perception that dimensions of science, which go beyond their alliances with the State and the market, are relevant to the challenges on the horizon of the 21's century.
\end{abstract}

Keywords: Cinema. Bergson. Science. Newton. Modernity.

\section{CINE Y CIENCIA, NATURALEZA Y CULTURA}

\section{Resumen:}

Frente a los problemas contemporáneos que cuestionan las fronteras entre naturaleza y cultura, el hombre y la máquina, sociedad y medio ambiente, el cine se toma aquí como una guía para la reflexión sobre la ciencia moderna a partir de textos de Bergson, Deleuze y otros autores. Operando un pasaje de la ciencia al arte y del arte a la ciencia, el cine se supone aquí como objeto técnico y el objeto técnico como instrumento de aumento de percepción. La ley de la atracción gravitacional de Newton, reconocida como el mayor logro de la ciencia moderna, es tratada en el texto en sus implicaciones físicas y metafísicas con base en los escritos de Betty Dobbs y de Newton para resaltar la artificialidad de estas fronteras. A través de la lente del cine, especialmente las películas 2001, odisea del espacio, de Stanley Kubrick y Out of the present, de Andrei Ujica, el artículo muestra el poder del cine para la percepción de que las dimensiones de la ciencia que van más allá de sus alianzas con el Estado y el mercado son relevantes para los desafíos en el horizonte del siglo XXI.

Palabras clave: Cine. Bergson. Ciencia. Newton. Modernidad. 


\section{REFERÊNCIAS}

ANDRADE, Carlos Drummond de. Poesia e prosa. Rio de Janeiro: Nova Aguilar, 1992.

BENJAMIN, Walter. Walter Benjamin. Obras escolhidas. Magia e técnica, arte e política. São Paulo: Editora Brasiliense, 1987.

BERGSON, Henri. As duas fontes da moral e da religião. Rio de Janeiro: Zahar, 1978. Durée et simultanéité. Paris: Quadridge/PUF, 1998.

A evolução criadora. Lisboa: Edições 70, 2001.

Memória e Vida. Textos escolhidos por Gilles Deleuze. São Paulo: Martins $\overline{\text { Fontes, }} 2006$.

Matéria e Memória. São Paulo: Martins Fontes, 2010.

CARBONE, Mauro. La chair des images: Merleau Ponty entre peinture et cinema. Paris: Vrin, 2011.

DELEUZE, Gilles. Bergsonismo. Rio de Janeiro: Nova Fronteira, 1999.

A imagem-tempo. São Paulo: Brasiliense, 2005.

DOBBS, Betty Jo Teeter. The Foundations of Newton's Alchemy. New York: Cambridge University Press, 1984.

DELEUZE, G.; GUATTARI, F. O que é a Filosofia? Rio de Janeiro: Editora 34. 1992.

2011.

.Mil platôs: capitalismo e esquizofrenia - vol. 1 São Paulo: Editora 34,

EPSTEIN, Jean. L'Intelligence d'une machine. Paris: Jacques Melot, 1946. 
.Ecrits sur le cinema. 1921 - 1953. Paris: Seghers, 1974.

GODDARD, Jean-Cristophe. Notas sobre A queda do céu de Davi Kopenawa y Bruce Albert por un lector blanco. ClimaCom Cultura Científica. Campinas, ano 03, n.05, abr. 2016. Disponível em: <http://climacom.mudancasclimaticas.net/?p=4967>. Acesso em 15 Jun. 2016.

HAMBURGER, Amélia Império. Alquimia e o sincretismo racional de Newton. ATAS XII Simpósio nacional de ensino de física. Belo Horizonte, 1997.

HILL, Cristopher. 0 mundo de ponta cabeça. São Paulo: Companhia das Letras, 1987.

KOYRÉ, A. Études newtoniennes. Paris: Gallimard, 1968.

KOPENAWA, Davi e ALBERT, Bruce. A queda do céu. São Paulo: Companhia das Letras, 2015.

KOPENAWA, Davi. Depoimento recolhido em 1998 na aldeia onde vive. Traduzido e editado por Bruce Albert. Disponível em < https://pib.socioambiental.org/pt/c/nobrasil-atual/narrativas-indigenas/narrativa-yanomami ‥ Acesso em 14 Jun 2016.

LATOUR, Bruno. Jamais fomos modernos. Rio de Janeiro: Editora 34, 1994.

LINDEN, Stanton. The alchemy reader. From Hermes Trismegistus to Isaac Newton. Cambridge: Cambridge University Press, 2003.

LEPERCHEY, Sarah. Des modèles topologiques pour l'analyse de film. Alliage, n. 71. Nice, hiver 2012-2013.

MACHADO, Arlindo. Pré-cinema e pós-cinema. Campinas: Papirus. 2013.

MERLEAU PONTY, Maurice. Fenomenologia da percepção. São Paulo: Martins Fontes, 1999.

NEWTON, Isaac. Principios matemáticos de la filosofía natural, 2. Madrid: Alianza Editorial, 1987. 
Óptica. São Paulo: Edusp, 1996.

.As profecias do apocalipse e o livro de Daniel. As raízes do código da Bíblia. São Paulo: Editora Pensamento, 2008.

PIASSI, Luis Paulo de Carvalho. Interfaces didáticas entre ciência e cinema. Um estudo a partir de 2001: uma odisseia no espaço. São Paulo: Editora da Livraria da Física, 2013.

SANTOS, Laymert Garcia dos. Politizar as novas tecnologias. São Paulo: Editora 34. 2003.

.O fim de um mundo. Revista Caros Amigos. São Paulo: Edição 230, 2016.

SIMONDON, Gilbert. Du mode d'existence des objets techniques. Paris: AubierMontaigne, 1969.

TARKOVSKI, Andrei. Esculpir o tempo. São Paulo: Martins Fontes. 1990.

VIRILIO, Paul. A Bomba informática. São Paulo: Estação Liberdade, 1999.

VIVEIROS DE CASTRO, Eduardo. O recado da Mata. In: KOPENAWA, D.; ALBERT, B. A queda do céu. São Paulo: Cia. Das Letras, 2015. p.11-42.

WESTFALL, Richard. Never at rest. New York: Cambridge University Press, 1980.

\section{FIGURAS}

Figura 1 Disponível em: http://ocorvo.pt/wpcontent/uploads/2014/10/Out of the Present 51-470x330.jpg Acesso em 29 Jul. 2016.

Figura 2 Disponível em: http://scibreak.com.br/wp-content/uploads/2015/11/newtons-cannoball-menor.jpg Acesso em 29 Jul. 2016.

Artigo:

Recebido em 01 de Agosto de 2016.

Aceito em 16 de Março de 2017.

R. Inter. Interdisc. INTERthesis, Florianópolis, v.14, n.2, p.19-38 Mai.-Ago. 2017 